\title{
Scaffolding Oriented Cognitive Perturbation as an Alternative Solution on Covid-19 Learning Era
}

\author{
Rendy Wikrama Wardana* and Afrizal Mayub \\ Graduate School of Science Education, University of Bengkulu \\ *Corresponding author. Email: rendywardana@unib.ac.id
}

\begin{abstract}
The Covid-19 pandemic has impact on education and learning aspects. Learning evolves into less effective because the student demanded to self-regulate learning with all the obstacles. Appropriate learning method is needed as an alternative solution in learning processes. One of them is Scaffolding and Cognitive Perturbation Learning. This research aims to examine the Scaffolding oriented Cognitive Perturbation as one of the learning alternatives in Covid19 era. This research was a qualitative research with literature review design. Data collection was conducted by collecting some literatures either articles and books related to scaffolding learning and cognitive perturbation. Data analysis was conducted by analysis and synthesis articles or books and then drew a conclusion. The research result shows that the scaffolding oriented cognitive perturbation was effective and efficient as the learning solution in Covid-19 era
\end{abstract}

Keywords: Scaffolding, Cognitive Perturbation, Learning, Covid-19.

\section{INTRODUCTION}

Covid-19 is one of the diseases that has a major impact in Indonesia in terms of health, economy and education. Several government programs in the field of education have not been optimal. For example, schools and colleges cannot carry out learning in the class by requiring all students to learn from home. The implementation of education policies during the Covid19 emergency is regulated in a circular letter from the Ministry of Education and Culture Number 4 of 2020. This letter shows the provisions of the Learning from Home process through online or distance learning. Learning activities are carried out to provide meaningful learning experiences for students without being burdened by demands for curriculum achievement and determining class promotion or graduation.

Home learning activities are focused on life skills education. Home learning activities and assignments can vary between students according to interests and conditions, including gaps in access and learning facilities at home. The lack of effectiveness of students in learning independently with all the limitations that exist is a problem in the learning process. Based on a field study conducted on fourth semester students in one of the Master study programs in the city of Bengkulu, it shows that some courses are difficult to understand and less optimal when studying online and independently. For example, the science education research statistics course. Statistics courses are the basis and guidelines for data processing techniques for students' final assignment (thesis). Students tend to process data directly using a system where the results of the data come out immediately without understanding how the data processing occurs, and are less careful in using statistics in the final project.

Learning will be maximized if it is supported by a structured, systematic learning design and can provide access to material that is easy for students to understand. Therefore it is necessary to develop a learning design that can be implemented in accordance with some of the problems that exist today. A good learning design certainly has the right model, approach, strategy, learning method and according to the characteristics of the learning material. One of the learning methods is the Scaffolding method. Scaffolding learning can be interpreted as a way of providing learning support independently, structured from the initial stage to the final stage. Provision of support is carried out continuously in the form of conceptual support and conceptual interference that cause students to change 
existing concepts in them. One of the cognitive disorders in the theory of concept change is Cognitive Perturbation. Cognitive perturbation is defined as cognitive disorders faced by students based on conceptions and knowledge of a concept [1]. The limited research on cognitive perturbation in the context of learning becomes the basis for further study in the learning design preparation process

This research aims to carry out analysis and synthesis related to appropriate learning methods and to build students' concepts during the Covid-19 pandemic. Based on some information and existing problems, this research is entitled "Scaffolding Oriented Cognitive Perturbation As an Alternative Solution in Covid-19 Learning Era".

\section{RESEARCH METHODS}

Research is a qualitative study with the literature design review. Qualitative research describes an understanding of the phenomena experienced by research subjects, such as behavior, motivation, action holistically by means of descriptions in the form of words and language in a special natural context by utilizing various scientific methods [2]. Data collection was conducted through a study of reading sources, particularly journalrelated Scafolding and Cognitive Perturbation with the context of learning. Data analysis was conducted by analyzing and synthesizing journals which were then drawn a conclusion.

\section{RESULTS AND DISCUSSION}

Covid-19 Pandemic impacts various aspects of life, one of which is education. Learning process is more optimized on online learning activity. Online learning certainly has impact on science learning materials. Science learning material is required to understand the theory and practice in learning process. One of science learning obstacles in online learning is limited practice activity and material delivery that are conducted through lecture only. It makes the science learning felt difficult and boring. The learning process obstacles faced during Covid-19 Pandemic can be overcomed if the learning design is arranged structurally and systematically in line with the condition and characteristics of the material

The learning design covers all process conducted at certain system which covers the stages such as analysis, design, development, implementation, and evaluation [3]. Learning design has stages which describe someone's learning process from the beginning until the end of the learning [4]. Learning design is meant as the grids from the learning theory implementation and learning to facilitate someone's learning process [5]. Based on some those definitions, it can be concluded that learning design is certain learning procedure arranged structurally and systematically from the stages of analysis, design, development, implementation, and evaluation which result maximal learning output

A good learning design certainly has precise model, approach, strategy, and learning method that are suitable with the learning materials. One of learning strategy alternatives in arranging the learning design is Scaffolding. The strategy which can be selected by the teacher to assist students' difficulty in studying especially in new material is Scaffolding [6]. Scaffolding has meaning as the ladder or certain arrangement connected in certain system. The stages of Scaffolding learning cover intention, appropriateness, structure, collaboration, and internalization [7].

Scaffolding is certain learning process which occurs on the children when they learn to finish the assignment that is not learned and in their ability range [8]. The students will be difficult if they find new problem that is not in their ability range in learning certain concept. The foundation or basic of scaffolding method is constructivism theory. This means that the students construct the knowledge obtained independently during the learning process. Scaffolding can diagnose and improve students' understanding in the learning process [9].

Learning by using Dialogic Scaffolding has the potency to give explanation and more interaction from the teacher and the students in the effort to improve understanding and practical learning in school context [10]. Scaffolding strategy can be arranged in certain design framework which can be made as alternative of problem solving through learning technology usage [11]. Scaffolding learning assisted by computer has significant effect towards science learning [12]. Scaffolding Learning assists the students to improve observation skill, criticizing, arranging order system in observation activity [13]. This result shows that Scaffolding learning is effective for practice course. Technology in the form of pictures can facilitate scaffolding learning especially constructing the students' mental model [14].

Based on some definitions of scaffolding learning according the previous experts, it can be concluded that scaffolding learning is certain way of giving learning support independently, structured from the initial stage until the final stage. Providing support is done continuously either in the form of giving the concept or giving the conceptual interruption which cause the students to be capable of changing the existed concept in them. Scaffolding learning can be defined as the way of giving learning support independently, structured from the initial stage until the end. Providing support is conducted continuously in the form of conceptual support and conceptual interruption which causes the students to change the existed concept

One of cognitive interference in conceptual change theory is Cognitive Perturbation. The fundamental idea of cognitive perturbation is based on the understanding of conceptual change for the students are different and 
varied $[15,16]$. Cognitive perturbation is based on the learning constructivist theory which in its process providing precise cognitive interference to start the students' conceptual change before reaching the scientific conception [16]. Cognitive perturbation is meant as the cognitive interference faced by the students based on the conception or knowledge towards certain concept [1]. Providing cognitive interference in each learning stage can diagnose students' understanding level in comprehending certain concept. Cognitive perturbation can describe the conception and knowledge structure of the students in learning the concept [1].

Cognitive perturbation can be in the form of computer simulation usage, pictures, and questions in the form of cases or treatment stages in analyzing students' understanding. The usage of cognitive perturbation in each scaffolding learning stages is expected to diagnose students' understanding in learning structured concept from the beginning until the end of learning process. Based on the result of literature analysis, it can be concluded that the usage of scaffolding learning theory and cognitive perturbation can be made as one of solution alternative in learning during Covid-19 pandemic.

\section{CONCLUSIONS}

Scaffolding has a meaning as a ladder or an arrangement that is connected in a system. Scaffolding learning can see the process and facilitate student learning in completing tasks that have not been studied and are within its ability. Scaffolding learning can be interpreted as a way of providing learning support independently, structured from the initial stage to the final stage. Provision of support is carried out continuously in the form of conceptual support and conceptual disturbances that cause students to change existing concepts in them. One of the cognitive disorders in the theory of concept change is Cognitive Perturbation. Cognitive disorders can show the extent to which students understand the concept.

\section{REFERENCES}

[1] Wardana, R. W., Liliasari., Tjiang, P. C., and Nahadi. (2017). Kajian Konsepsi Intermediate dan cognitive perurbation mahasiswa pendidikan fisika lintas level akademik Pada konsep listrik magnet. [Disertasi Universitas Pendidikan Indonesia].

[2] Moleong, L. J. Metode penelitian kualitatif. Bandung : PT Rosdakarya. 2007.

[3] Dick, W. And Carey, L. The Systematic Design of Intructional. Glecview, Illionis: Scot, Foresman and Company, 1992.
[4] Gagne,Briggs dan Wager. Principle of Instructional Design. Second. Edition,Holt, Rinehart and Winston; New York. 1992.

[5] Reigeluth, Charles, M. Instructional-Design Theories and Models. United State of America. Electronic Pablicing Servicies, Inc. 1992.

[6] Sutiarso, Sugeng. Scaffolding dalam pembelajaran Matematika. Prosiding seminar nasional penelitian dan Penerapan MIPA UNY. 2009.

[7] Applebee, N.A and Langer, A.J. Instructional Scaffolding : Reading and Writing as Natural Language Activities. Journal of Computer Assisted Learning. 1983

[8] Trianto. Model Pembelajaran Terpadu. Jakarta: Bumi Aksara. 2010.

[9] Van de pol, J. \& Elbers, Ed. Scaffolding student learning : A micro-analysis of teacher - students interaction. Learning,culture and social interaction, 2013. 32-41.

[10] Rojas-Drummond, Torreblanca. O, Pedraza. H, Velez. M \& Guzman. K.. Dialogic Scafofolding : Enchaching learning and understanding in collaborative contexts. Learning, Culture and Social Interaction. 2013. 11-21.

[11] Kim, M.C \& Hannafin, M. J. Scaffolding problem solving in technology-enchanched learning environments (TELEs) : Bridging research and theory with practice. Computer \& Education 2011. (56) 403 - 417

[12] Davolder, A, Braak, J.V and Tondeur, J. Supporting self-regulated learning in computerbased learning environments: systematic review of effects of scaffolding in the domain of science education. Journal of Computer Assisted Learning. 2012.

[13] Chang, H.Y and Linn, M.C. Scaffolding Learning From Molecular Visualizations. Journal of Research in Science Teaching, 2013. 50 (7), 858886.

[14] Eitel, A., Scheiter. K, Schuler. A, Nystrom. M, \& Holmqvist. K. How a Picture facilitates the process of learning from text : Evidence for scaffolding. Learning and instruction. 2013. 28 (48-63).

[15] Li, S. C. Cognitive perturbation and conceptual change in learning about marine ecology withdynamic modeling. International Journal of Instructional Media, 2011. 38(4), 359-367.

[16] Li, S. C., Law, N., and Lui, K. F. A. Cognitive perturbation through dynamic modeling:A pedagogical approach to conceptual change in science. Journal of Computer Assisted Learning, 2006. 22(6),405-422. 